\title{
Economic opportunities for Demand Response by Data Centers within the new Italian Ancillary Service Market
}

\author{
Filippo Bovera \\ Department of Energy \\ Politecnico di Milano \\ Milan, Italy \\ filippo.bovera@polimi.it
}

\author{
Maurizio Delfanti \\ Department of Energy \\ Politecnico di Milano \\ Milan, Italy \\ maurizio.delfanti@polimi.it
}

\author{
Fabio Bellifemine \\ Innovation - Business Positioning \\ TIM \\ Turin, Italy \\ fabioluigi.bellifemine@telecomitalia.it
}

\begin{abstract}
The exploitation of Demand Response as an effective dispatching resource is strictly linked to the new economic opportunities for consumption units deriving from the participation to the Ancillary Services Market. This study provides evidence of the fact that Data Centers, thanks to backup generation and storage systems present at their sites, can be exploited as flexible consumption units for Demand Response purposes. Results highlight how the remuneration mechanisms foreseen for the market activity, and the sizing and operation of local assets, are of utmost importance in guaranteeing the worth of potential investments made by Data Centers' owners to adapt the consumption sites for the provision of ancillary services.
\end{abstract}

Keywords—demand response, capacity remuneration, flexibility

\section{INTRODUCTION}

The global energy framework is undergoing profound changes. New economic dynamics are reshaping the map of energy consumption, with a forecast of growth in global energy demand over the next few decades that is uneven and concentrated in some specific geographical areas. On top of this scenario, international scientific communities are concerned by the risks and costs associated with climate changes. The COP21 conference, in December 2015, led to the definition of the Paris Agreement, which sets as a longterm objective the containment of the increase in temperature below $2{ }^{\circ} \mathrm{C}$. In the wake of international agreements, European Union has strengthened its low-carbon targets to 2030 [1], with the aim of making the Union's economy and energy system safer, more competitive and more sustainable.

In this context, end consumers are considered to have a new role in the electricity system, making them active protagonists and no longer passive users merely receiving a service. A major involvement of consumption units in electric grid management has started in Italy with the Ancillary Services Market (ASM) reform in 2013 [2]: regulatory solutions, concerning market design, remuneration mechanisms and aggregation boundaries, are currently under investigation through some specific pilot projects issued by the Italian Transmission System Operator (TSO), namely TERNA [3].

Literature concerning the management of end-users flexibility is mainly devoted to households and small residential communities (for the Italian case, see [4] and [5]). Differently, this work is intended to provide an evaluation of the possibility to exploit Data Centers (DC) as dispatching resources within the opening market framework described above. In particular, specific attention is devoted to the layout of energy facilities capable to ensure an effective modulation of DC load. Also, a deep analysis of the economic profitability of the service is provided.
The study is carried out considering different scenarios for the working operations of the diverse energy facilities present in a Data Center; in particular, the possibility to use Energy Storage Systems (ESS) and diesel backup generators is investigated as a possible solution to provide the load flexibility required on the ASM.

It will be shown that the presence of a suitable payment based on the capacity made available by the DC (remuneration in $€ / \mathrm{MW}$ ), together with a free-market participation allowance (with a remuneration in $€ / \mathrm{MWh}$ ), allow obtaining good economic results, and make the investment worth especially if sizing of the generation assets exploited locally is tuned with respect to the requirements by the TSO and to the volumes traded on the market.

The remainder of the paper is organised as follows: Chapter II introduces the ASM reform ongoing in Italy, while Chapter III provides an overview of the main aspects influencing the management of demand to provide ancillary services. Chapter IV describes the Data Center case study, with the assumptions considered, while Chapter V reports in details the scenarios developed. Finally, Chapter VI points out the main conclusions of the simulations performed.

\section{ASM REFORM ONGOING IN ITALY}

The EU decarbonisation targets have fostered (especially in some countries, like Italy) a rapid diffusion of Renewable Energy Sources (RES) and of Distributed Generation (DG), mainly driven by non-programmable photovoltaic and wind plants. The massive presence of these new sources asks for an evolution of the regulatory framework to fully integrate such actors in the procedures aimed at the electric system management [6].

In particular, due to the reduced on-line control capacity, to the increased need of scheduled reserve margins (secondary and tertiary), and to the increased use of resources with rapid activation (spinning reserve), the system requires a greater amount of flexible resources for its secure operation. Services needed regard mainly power reserve (upward and downward), possibly provided by plants characterized by high operating flexibility. Such services can be obtained mandatorily, as a result of technical requirements set by the TSO, or on the base of a free market activity [7]. The use of these flexible resources fosters the capability of the electric network to respond to the increasing imbalances between generation and demand [8], which are in essence due to the increasing share of non-programmable RES. 


\section{A. Current status of ASM in Italy}

As for the Italian power system, more than $30 \mathrm{GW}$ of the production capacity are currently represented by nonprogrammable energy resources, and more than $20 \mathrm{GW}$ come from units connected to the Distribution Network (DN) [9]: an important share of the production units is not contributing to the efficient and secure operation of the electric system. These units are not enabled to participate to the ASM, and thus do not provide any dispatching resources.

In fact, the ASM currently in place system is based only on Production Units (PUs) fed by coal, natural gas and hydro resources (in the latter case, only programmable PUs are admitted). There is a minimum size of 10 MVA for PUs participating to ASM, along with the need to be directly connected to the national transmission grid $^{1}$ : such PUs are of interest for ASM, and are defined "Relevant PUs".

It has to be highlighted that the remuneration for ASM participation is currently based on an "energy only" mechanism: only the energy dispatched (by means of proper dispatching orders issued by TERNA) is remunerated ( $€ / \mathrm{MWh})$; no payment is currently in place for the capacity made available for ASM.

\section{B. Pilot projects towards a new ASM}

The reform of the Italian ASM is in line with the indications provided in the Clean Energy Package at EU level, with particular reference to the European Parliament and Council regulation of the internal electricity market $\operatorname{COM}(2016) 861$ [10], and the Balancing Code [7].

In particular, observing the scarce availability of dispatching resources (linked to the increasing penetration of RES), the Italian Regulatory Authority (ARERA) started a process of reformation of the ASM [2]. The process (Riforma del Dispacciamento Elettrico) is addressed by the Deliberation 393/15 [11]; within the objectives of this reform, the opening of the market to new actors (including demand side) is a fundamental point.

The ARERA Deliberation 300/17 [12] has paved the way to the future dispatching model through specific pilot projects, that will allow three new entities to be enabled to the ASM platform, by means of aggregators:

- UPR (Unità di Produzione Rilevanti): Relevant Production Units (PUs) not enabled in ASM since they are non-programmable (typically RES);

- UVAP (Unità Virtuali Abilitate di Produzione): aggregations of PUs, including storage systems;

- UVAC (Unità Virtuali Abilitate di Consumo): aggregations of consumption units.

Under the coordination of an aggregator, production (or load) units can enrol to an UVA, which is enabled to participate to ASM.

Each PU belonging to an UVA must have a proper communication and control system connected to the relevant aggregator, to provide production and consumption data; in turn the aggregator will be linked to TERNA operating center, as visible in Figure II.1.

\footnotetext{
${ }^{1}$ The national transmission grid (Rete di Trasmissione Nazionale, RTN) is managed by TERNA, and includes EHV+HV grids (132/150/220/380 kV).
}

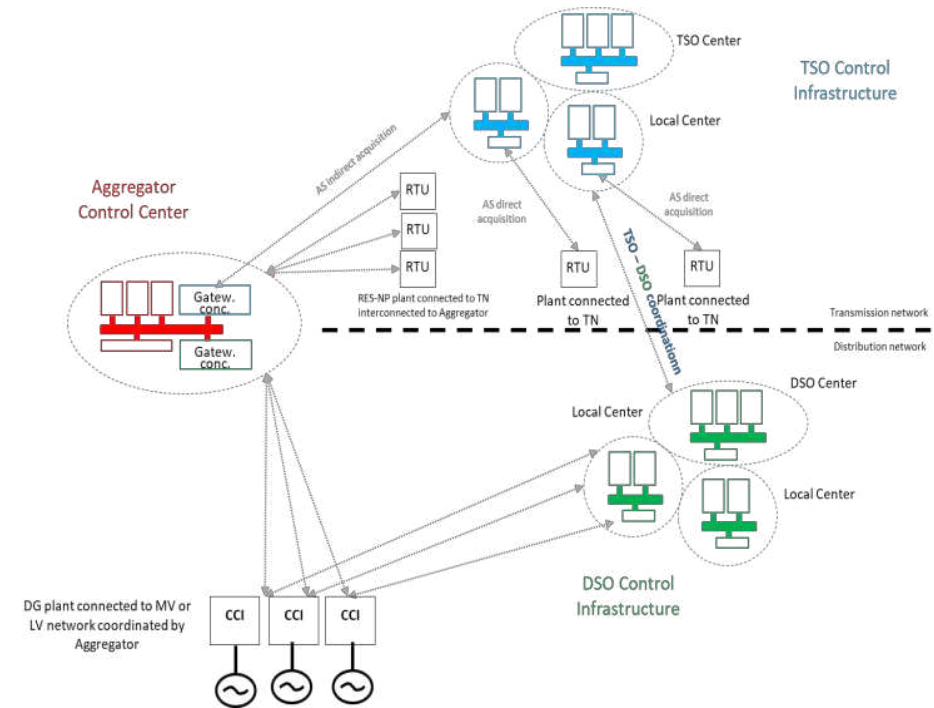

Figure II.1 - Communication and control architecture including aggregators and system operators

For the purpose of this paper, UVAC project, concerning demand response, is the most interesting. The participation of consumption units is possible with two different mechanisms, listed in the following [13].

\section{- Direct participation to ASM}

No remuneration is provided for capacity, hence no limit is given to the presented price, and quantity offered is free along the whole day. The UVA is remunerated only considering the reduction of withdrawn energy consequent to an ASM call $(€ / \mathrm{MWh})$

- Short term capacity contract

The UVA subscribes a contract with TERNA in which:

o TERNA remunerates the unit for the capacity made available $(€ / \mathrm{MW})$, with a fixed price defined by a capacity auction, and for the energy consumption reduction $(€ / \mathrm{MWh})$ with a cap of $400 € / \mathrm{MWh}$ for the bids presented on the market.

o The operator makes available its capacity for minimum 3 hours per day between 14:00 and 20:00 in at least $70 \%$ of the contracted period.

Each UVA has to respect the geographical perimeters defined by TERNA, as shown in Figure II.2.

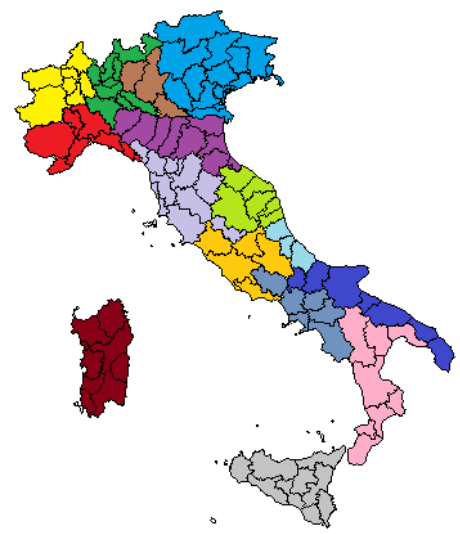

Figure II.2 - Aggregation perimeters defined. 


\section{THE ROLE OF DEMAND MANAGEMENT}

Opening the market to demand could offer consumers an opportunity for active participation in the management of the system, also thanks to the exploitation of new technological solutions for telecommunication networks, and an occasion for possible savings, through the introduction of market competition mechanisms [14]. The first step for evaluating the economic opportunities deriving from the opening of the market to consumption units consists in analysing the potential for the use of diverse technologies in order to modulate effectively the power exchanged with the electric grid.

Unlike what can be obtained from production plants or storage systems, it should be noted that the use of loads (industrial, commercial, domestic) as flexible resources generally involves the possibility of using existing assets (typically installed for other purposes), entailing an advantage in terms of initial investment. Since many consumption facilities include energy replacement resources, installed for reasons linked to service reliability (e.g. Uninterruptible Power Supply, emergency generating sets) or to the efficiency of the overall energy supply (e.g. cogeneration systems), it is possible to exploit these resources. In this perspective, a synergy is obtained between the local functions carried out by these assets and the new flexibility services required by the electricity system.

It is possible to identify some key parameters, related to the flexibility of the consumption units, that are of great importance in the ancillary services provision panorama.

- Response dynamics: based on the characteristics of the underlying process and the use of the energy withdrawn from the network, the consumption unit may be more suitable for performing a rapid action (variation in seconds/minutes) or a slow one (a variation that develops in one hour). In the case of rapid action also other parameters become significant, such as the amplitude of power modulation and the modulation gradient.

- Durability: depending on the characteristics of the underlying process, the performance provided by the consumption unit can be sustained for a defined time (e.g.: one hour; six hours). The mediation of an aggregator (combining the action of more units over time) extends the possible participation of consumption units also to those loads which are characterized by short autonomy in withdrawal deferral.

- Frequency: based on the characteristics of the underlying process, the ASM performance may be provided with a frequency (e.g.: once a day) not exceeding a value compatible with the functionality of the plant. This parameter can also be expressed in terms of minimum waiting time between two modulation operations.

- Availability of the resource: according to the characteristics of the underlying process, the consistence of the ancillary service provided is timedependent, i.e. the amount of power that can be actually modulated may vary on an hourly, daily, weekly or seasonal basis.
- Presence of replacement resources: it should be noted that the withdrawal reduction is not necessarily achieved by reducing the electricity consumption; it is also possible to replace the grid energy with energy generated or accumulated within the site. For example, replacement may take place by means of:

o electrochemical storage systems, normally used to back-up the power supply in the event of a grid failure (interruption of few minutes);

o emergency generation units, typically activated in case of long lasting interruptions of the external power supply, that can sustain the load for a long period of time (up to one or more days).

- Costs of upgrading the plant: the interruption of the withdrawal must not lead to malfunctions in the plant components or significant problems in the production process (e.g. costs for restarts); any adjustment to the plant or changes in the production process to deal with the inconvenience caused by the interruption must have contained costs.

- Control systems and TLC infrastructures: in addition to the technical feasibility dictated by the underlying process, it is also necessary to consider any interventions for the monitoring and control of the system (e.g. installation of measuring equipment, control devices) along with the communication infrastructure needed to exchange real time signals with the aggregator (towards the TSO).

\section{DATA CENTERS AS SOURCES OF FLEXIBILITY}

Under the light of the observations made in Chapter III, Data Centers (DC) are one of the most promising consumption sites connected to the electric grid when considering the capability to provide flexibility for the network management.

Data Centers are an important category of load in the framework of electricity end-use in Italy, as in many other Member States of the European Union. In particular, a study promoted by the European Commission estimates that DC consumption in Europe will be 104 TWh by 2020 (while in the USA it will reach $140 \mathrm{TWh}$ ) [15]. Such installations are particularly suitable for flexibility services, as they are connected to busses of the electricity network characterised by a high quality of service. Also, the DC sites are provided with high performance TLC links, and thus do not need any costly improvement to get a suitable data connection to the aggregator's control center. In addition, the flexibility provided by one site is easily found at all similar installations. Finally, once a control structure has been designed and implemented for one DC site, it can be easily replicated to other sites.

In the following, the technical and economic feasibility of participation in flexibility services is studied for a single large DC, connected to the MV network, taking advantage of the different characteristics of the emergency power systems already installed (with suitable integrations about the UPS). 


\section{A. Structure of a Data Center}

Based on increasing levels of reliability, Data Centers can be classified according to ANSI-TIA 942 [16] as TIER $1,2,3,4$. The larger DC are built according to a scheme that provides power from the MV distribution network and an emergency power supply organized into two levels of local power sources, consisting of UPS and Generating Sets (hereinafter, GenSets).

Since Data Centers are designed to provide services with a superior reliability, the plant architecture reaches very high levels of sophistication.

From the point of view of the principle scheme, in the case of TIER 4 solution, the schematisation contained in Figure IV.1 can be used ${ }^{2}$; simpler solutions are obtained by reducing the more complex case.

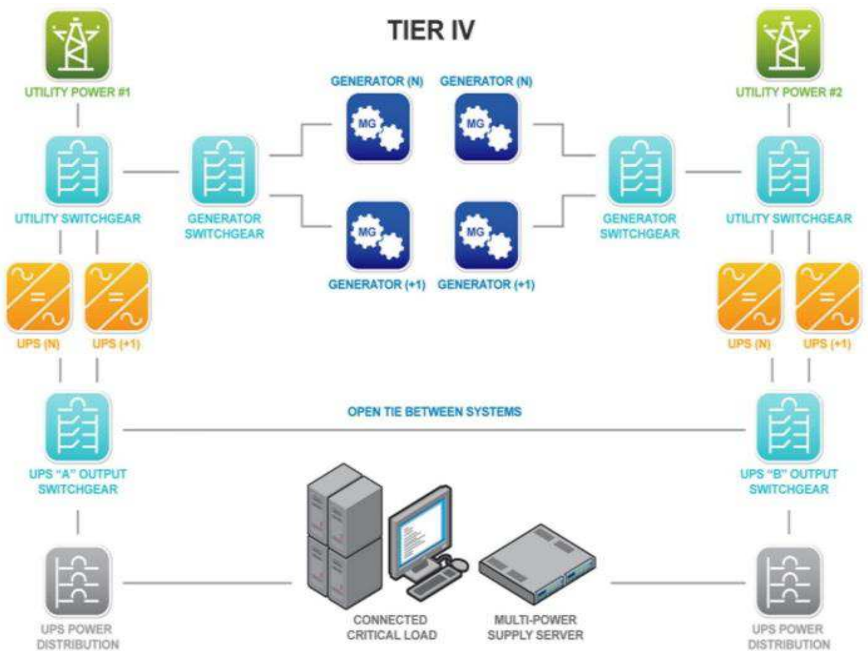

Figure IV.1 - Principle scheme of a Data Center (the figure has been elaborated for TIER 4 scheme of ANSI TIA 942).

As shown in the figure, for each of the branches of the plant (left and right), there are, in duplicate, appropriate emergency sources, consisting of both UPS and diesel GenSets. In particular, the operating logic requires that UPSs maintain a voltage waveform free from disturbances (for example, voltage dips) for critical loads (servers powered by alternating current): in fact, power supplies to DC end users need a very high voltage quality. In the event of an external power failure (e.g., a long interruption of supply), the UPS will be activated for the time necessary to start up the GenSets. Once an initial phase has passed, in which the absence of the external power supply is compensated for by the UPS, the GenSets come into operation, replacing the external power supply.

\section{B. Main assumptions}

\section{Load profile}

The load profile of a DC is usually constant, as the cooling systems are always active to evacuate the heat produced by the process machines; however, there is some day/night variation, as well as on a seasonal basis, linked to

\footnotetext{
2 For the sake of simplicity, the scheme does not present ventilation and air conditioning systems, which are supplied by the external grid (normal conditions) or by GenSets (emergency conditions, e.g. during an interruption of the distribution grid).
}

a different level of efficiency in the production of the refrigerants by the compression refrigeration units.

The consumption profile is characterised by a base load (about $80 \%$ ) that remains constant throughout the year; the most critical periods for air conditioning show a further $20 \%$ withdrawal from the grid.

\section{Uninterruptible Power Supply}

For UPSs employed in DC, accumulators of the Valve Regulated Lead-Acid (VRLA) type are mainly used. For the purpose of this study, it is imagined to replace the battery equipped with the UPS with a new storage system, of the Lithium-Ion technology, characterised by a suitable energy to power ratio (EPR). For this type of application, the overall efficiency of the storage systems varies from a minimum of $90 \%$ to a maximum of $95 \%$.

\section{Generating Sets}

The GenSets operating time depends on the diesel tank capacity. A common dimensioning consists in designing the tanks in such a way as to guarantee an autonomy of at least 24 hours. As far as the efficiency of the unit is concerned, for a GenSet around megawatts a value of about $35 \%$ can be assumed.

\section{Availability of local energy sources}

The provision of flexibility (grid services) and the main task (local supply for business continuity) are perfectly compatible as:

- if a call for grid services were to occur during an interruption on the local distribution network, the service could not be provided; however, given the high QoS levels of the Italian electricity system ${ }^{3}$, the simultaneous occurrence of a call for flexibility and an interruption on the distribution network has a negligible probability;

- should a supply interruption occur on the distribution network during flexible operation by the Data Center, the interruption of the external power supply would not cause any damage to critical loads (they are already supplied in emergency mode); the reduction required by the TSO would also be respected, as the withdrawal from the public network would remain unchanged with respect to the call received.

\section{THE CASE STUDY OF A FLEXIBLE DC}

Following Terna's pilot project on UVAC, which introduces the possibility of receiving a payment for a certain capacity made available by a final user for the service of upward reserve, two different remuneration mechanisms have been envisaged, which give rise to three different application scenarios.

${ }^{3}$ According to the Italian QoS regulation, the target value for SAIDI (System Average Interruption Duration Index) is 30 minutes per year. As illustrated in the following, the exploitation of DC as a flexible resource may take place for 500 hours per year. 
- SCENARIO 1: the flexible service is not remunerated with any payment in capacity, but only in energy. In this case it will be possible to freely manage the offers on the ASM, without any kind of obligation to bid or price cap.

- SCENARIO 2: the service is remunerated through a payment for both capacity and energy. In this case the payment in capacity implies an obligation to offer during the six hours between 14:00 and 20:00 on the working days, as foreseen by the UVAC pilot project; the yearly premium for guaranteed capacity for at least three out of the six hours belonging to the above mentioned interval is $30 \mathrm{k} € / \mathrm{MW}$.

- SCENARIO 3: the service is remunerated through a payment for both capacity and energy; GenSets are used to extend the range of services to six hours, obtaining a yearly premium of $60 \mathrm{k} € / \mathrm{MW}$.

\section{A. Local replacement resources and relevant management}

As for UPSs, for the simulations of this paper, it is assumed that VRLA batteries are replaced by a Lithium-Ion battery, rated $1 \mathrm{MW} / 3 \mathrm{MWh}(\mathrm{EPR}=3)$. The number of useful life cycles is considered equal to 5,000. The cost of this battery is estimated at $500 € / \mathrm{kWh}^{4}$. This figure is in line with what is found in literature and at the manufacturing companies for the type of ESS taken into consideration [17].

Since the ESS is intended to provide only an upward service, its reference State of Charge (SoC) is considered to be $100 \%$. Whenever possible, in compliance with the regulations related to the electricity market, the ESS will exchange energy in order to bring the value of its SoC to $100 \%$; therefore, it will be ready to guarantee the upward service on ASM.

As for GenSets, it is assumed a nominal power of $1 \mathrm{MW}$ (the same as UPS); from the technical standpoint, no new implementation is necessary, with respect to a real life DC.

\section{B. Service offered and relevant remuneration}

The reference prices for evaluating the operations of the flexible load on ASM are the prices recorded in the NORTH zone for offers of upward tertiary reserve [18]. In particular, Figure V.2 shows that where the value of the offer submitted is lower than the maximum price actually accepted on ASM in the considered period, the offer is deemed to have been accepted; if, on the other hand, the maximum price accepted in the period considered is lower than the value of the offer submitted, the offer is deemed to have been rejected. This mechanism is consistent with the principle of economic merit on which TERNA's operations on ASM are generally based.

\section{Simulation methodology}

The ESS used in the analysis is defined by a nominal power (Pn) equal to $1 \mathrm{MW}$ (power made available and declared for the purposes of ASM). In line with the requirements of the UVAC pilot project in terms of duration

\footnotetext{
${ }^{4}$ For the sake of simplicity, the cost is considered to depend only on the capacity of the batteries.
}

of service, the equivalent hours $\left(\mathrm{h}_{\mathrm{eq}}\right)$ are set at three, with nominal energy of $3 \mathrm{MWh}$, subsequently modified on the basis of the value of the efficiency defined for the battery taken into consideration. Charging and Discharging efficiencies are set at $90 \%$.

Simulations are conducted according to the following methodology.

- For each hour in which the ESS is able to guarantee a certain availability and feasibility of the service, and consistently with the timing of the various market sessions, an offer is presented for the upward service.

- The value of the bid submitted is fixed during each simulation (annual analysis), projecting the calculations subsequently on the useful life of the installation (e.g. 10 years).

- Six different simulations are carried out for each scenario, with a bid value of 150-200-250-300-350$400 € / \mathrm{MWh}$, thus respecting the bid cap imposed by the UVAC pilot project.

- If the maximum hourly price accepted on the ASM for upward tertiary reserve offers is higher than the value of the offer submitted, such offer is accepted.

- In the hours when no offer is submitted, or in the hours when the presented offer is not accepted, if the SoC of the ESS is not $100 \%$, energy is moved by charging the ESS through a withdrawal from the grid.

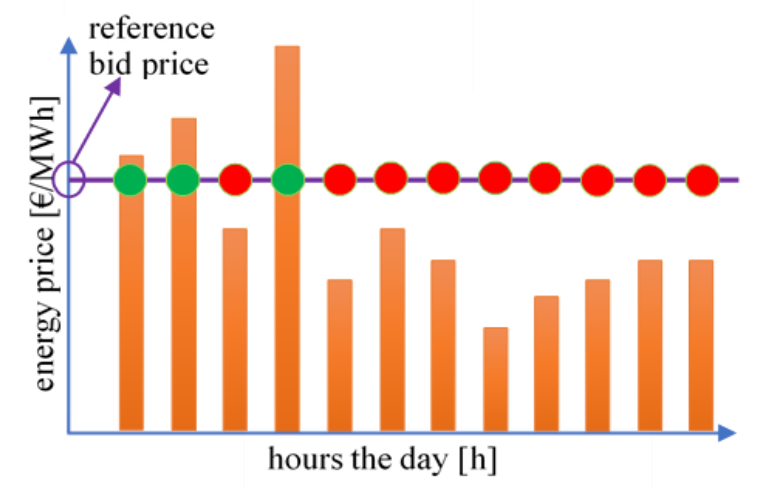

Figure V.2 - Bid acceptance mechanism: green dots if bid is accepted.

In the calculation of the monetary flows, consistently with the UVAC pilot project, the payment to the trader from which the energy is purchased of a quota equal to the PUN ${ }^{5}$ multiplied by the quantity offered for the upward service on ASM is considered, if the service is performed with ESS. In the case of the use of GenSets, in addition to the portion to be returned to the trader, a cost is assumed equal to the difference between the cost of generation $(250 € / \mathrm{MWh})$ and the cost of purchase from the network (PUN + charges + network costs + taxes $=$ about $150 € / \mathrm{MWh})$.

\footnotetext{
${ }^{5}$ PUN stands for Prezzo Unico Nazionale (single national price): it is the uniform price charged to customers over the entire Italian territory. It is calculated as the weighted average of the different zonal prices that appear in the 6 market zones of the Italian system. A typical value for PUN is about $50 € / \mathrm{MWh}$.
} 


\section{Economic KPIs}

The evaluation of the main economic parameters was carried out considering the following items:

- Revenue from energy trading on the ASM $\left(\mathrm{R}_{1}\right)$.

- Revenue from remuneration of capacity (if any) $\left(\mathrm{R}_{2}\right)$.

- ICT compliance cost $\left(\mathrm{C}_{1}\right)$, set at zero as the resource is concentrated at a single site and not distributed.

- Cost of upgrading the plant $\left(\mathrm{C}_{2}\right)$, consisting of the investment cost for the batteries (1.66 M€ for 3.3 $\mathrm{MWh}$ ) and the control infrastructure on the site (the latter amounting to approximately 10,000 €).

- Operating costs $\left(\mathrm{C}_{3}\right)$ associated with ICT adjustment and plant adjustment (about 2,000 €/year).

- Cost associated with the additional energy taken from the grid as a result of the losses of the ESS $\left(\mathrm{C}_{4}\right)$;

- Money returned as a refund to the trader responsible for the electricity supply service $\left(\mathrm{C}_{5}\right)$.

- Cost of diesel fuel for GenSets $\left(\mathrm{C}_{6}\right)$.

The payback period of the investment (simplified method of the Pay-Back Period - PBP) is therefore:

$$
P B P=\frac{C_{1}+C_{2}}{R_{1}+R_{2}-C_{3}-C_{4}-C_{5}-C_{6}}
$$

The $\mathrm{R}_{2}$ component should only be considered for Scenario 2 and Scenario 3, where the capacity remuneration is also expected; the $\mathrm{C}_{6}$ component should only be considered for Scenario 3, where GenSets are expected to be used.

The Net Present Value (NPV) is calculated over 10 years, with an inflation rate of $1 \%$; the NPV is set to zero if the estimated useful life of the ESS is less than 10 years.

Useful life is calculated in terms of total energy managed by the battery over the whole time of the simulation; in details, the volume of energy that can be exchanged by the battery before the end of technical life is calculated as the nominal capacity $\left(E_{n}\right)$ multiplied by the number of cycles.

\section{NUMERICAL SIMULATIONS}

In this chapter, the results of numerical simulations related to each scenario are reported.

\section{A. SCENARIO 1: no capacity payment.}

In this scenario no payment for available capacity is expected, therefore the entire profit derives from market negotiations in terms of energy $(€ / \mathrm{MWh})$ for sale (ASM) and purchase $\left(\mathrm{DAM}^{6}\right)$. Results show that the bidding at the Cap value $(400 € / \mathrm{MWh})$ is not convenient, since the ESS remains largely underutilized; this leads to a PBP not compatible with investment initiative. TABLE VI.1 shows the results of the simulations for scenario 1: colums refer to the Payback Period (PBP), the ESS lifetime, the Net Present Value calculated over 10 years, the annual profit and the amount of energy traded on ASM for different offer levels.

\footnotetext{
${ }^{6}$ Day-Ahead Market: it is the wholesale market where energy is traded typically in big amounts.
}

TABLE VI.1 - RESULTS OF THE SIMULATIONS FOR SCENARIO 1.

\begin{tabular}{|c|c|c|c|c|c|}
\hline $\begin{array}{c}\text { Offer } \\
{[€ / M W h]}\end{array}$ & $\begin{array}{c}\text { PBP } \\
{[\text { years] }}\end{array}$ & $\begin{array}{c}\text { ESS Life } \\
{[\text { [years] }}\end{array}$ & $\begin{array}{c}\text { NPV_10y } \\
{[€]}\end{array}$ & $\begin{array}{c}\text { Profit } \\
{[€ / \text { year] }}\end{array}$ & $\begin{array}{c}\text { MWh } \\
\text { on ASM }\end{array}$ \\
\hline 150 & 12.18 & 4.81 & - & 137,690 & 1,560 \\
\hline 200 & 12.07 & 7.40 & - & 138,898 & 1,014 \\
\hline 250 & 13.53 & 11.33 & $-502,996$ & 123,919 & 662 \\
\hline 300 & 12.62 & 13.43 & $-418,383$ & 132,852 & 558 \\
\hline 350 & 12.66 & 16.29 & $-422,269$ & 132,442 & 460 \\
\hline 400 & 34.16 & 50.68 & $-1,211,773$ & 49,084 & 148 \\
\hline
\end{tabular}

The PBP remains almost unchanged when the bid value changes from $150 € / \mathrm{MWh}$ to $350 € / \mathrm{MWh}$, meaning that an increase in the value of energy price obtained is offset by a decrease in the amount of traded energy. Together with the amount of energy exchanged, as the bid price increases, the amount of energy traded on ASM also decreases. Useful lifetime decreases rapidly as the value of the offer submitted decreases, and it is lower than the PBP for values below 250 $€ /$ MWh (Figure VI.1).

In Figure VI.1 it is possible to observe the relationship between PBP and the expected life of the ESS for different values of the bid price presented on the market.

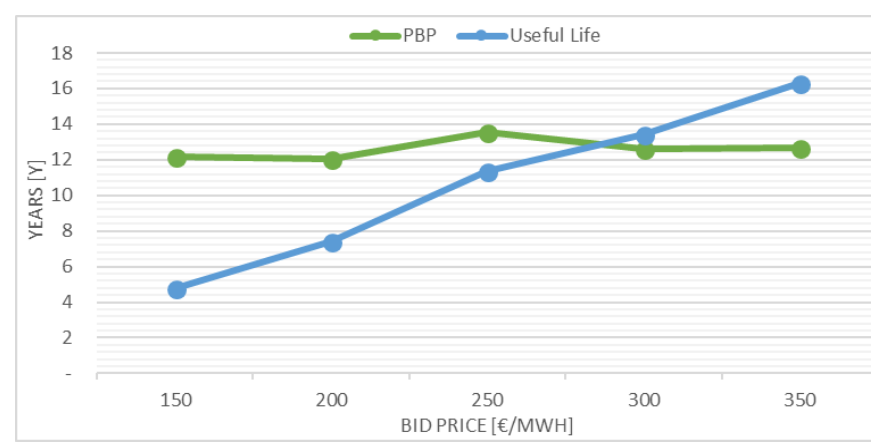

Figure VI.1 - PBP and useful life for the ESS in terms of years: while PBP remains constant, the lifetime of the ESS increases as bid price increases.

While PBP remains almost constant, life years decline rapidly as the value of bid price decreases. As highlighted, this is linked to the fact that, while offer price decreases, the amount of traded energy increases, and the battery reaches the end of technical life in a shorter time.

As a consequence, NPV (when defined) is strongly negative, indicating that the investment is not viable.

\section{B. SCENARIO 2: capacity payment considered.}

In this scenario, the presence of a capacity payment (yearly premium of $30 \mathrm{k} € / \mathrm{MW}$ ) makes it mandatory that the DC bids its capacity over a predefined time horizon (14:00 to 20:00 of every working day of the contracted period). This constraint alters the bidding strategy of the DC, preventing bids in more profitable hours.

The effect is visible in TABLE VI.2: market action of Scenario 2 is partly influenced by the obligation to bid in the specified period; as a result, the volume of energy traded, compared to Scenario 1, is reduced.

As for economic indicators, PBP is now shorter, due to the capacity premium; NPV remains strongly negative. 
TABLE VI.2. - RESULTS OF SIMULATIONS FOR SCENARIO 2.

\begin{tabular}{|c|c|c|c|c|c|}
\hline $\begin{array}{c}\text { Offer } \\
{[€ / M W h]}\end{array}$ & $\begin{array}{c}\text { PBP } \\
{[\text { years] }}\end{array}$ & $\begin{array}{c}\text { ESS Life } \\
{[\text { [years] }}\end{array}$ & $\begin{array}{c}\text { NPV_10y } \\
{[€]}\end{array}$ & $\begin{array}{c}\text { Profit } \\
{[€ / \text { year] }}\end{array}$ & $\begin{array}{c}\text { MWh } \\
\text { on ASM }\end{array}$ \\
\hline 150 & 10.04 & 4.90 & - & 165,949 & 1,531 \\
\hline 200 & 10.06 & 7.63 & - & 165,632 & 983 \\
\hline 250 & 10.99 & 11.63 & $-230,444$ & 151,639 & 644 \\
\hline 300 & 10.53 & 14.04 & $-168,015$ & 158,230 & 534 \\
\hline 350 & 10.71 & 17.36 & $-192,453$ & 155,650 & 432 \\
\hline 400 & 22.54 & 59.06 & $-966,403$ & 73,935 & 127 \\
\hline
\end{tabular}

C. SCENARIO 3: extended capacity payment and GenSets.

In Scenario 3 the possibility of supporting the ESS with GenSets is considered. GenSets are used to obtain an increase in the availability of the DC to reduce load. In particular, within the time interval of the offer obligation, a better durability is obtained, passing from three hours of guaranteed service (Scenario $1 \& 2$, as allowed by the size of the ESS), to the possibility of covering the entire obligation interval of six hours. The extension of the capability period allows to obtain a capacity premium of 60 $\mathrm{k} € / \mathrm{MW} /$ year instead of $30 \mathrm{k} € / \mathrm{MW} / \mathrm{year}$, as in previous Scenarios. This gain is achieved with a very limited investment cost, since GenSets are already present on site and their new function does not involve a particularly intensive use. In addition, the operating costs of the GenSets must a be taken into account: for this study only the cost of diesel fuel has been considered, since the normal maintenance costs are already borne within the management of the Data Center in common practice.

Actually, the annual occurrences in which the entire capacity of the ESS (which is worth three equivalent hours) is exploited are very limited. In particular, with reference to Scenario 2, the following number of occurrences of full capacity utilisation $\left(>2 \mathrm{~h}_{\mathrm{eq}}\right)$ have been observed:

- offers for $150 € / \mathrm{MWh} \rightarrow 216$ events;

- offers for $200 € / \mathrm{MWh} \rightarrow 125$ events;

- offers for $250 € / \mathrm{MWh} \rightarrow 80$ events;

- offers for $300 € / \mathrm{MWh} \rightarrow 68$ events;

- offers for $350 € / \mathrm{MWh} \rightarrow 57$ events;

- offers for $400 € / \mathrm{MWh} \rightarrow 7$ events.

For the economically significant offer values (greater than $250 € / \mathrm{MWh}$ ), the full capacity utilization is required for less than 80 occurrences per year; in all remaining cases, the capacity of 2 equivalent hours is sufficient. On the basis of this observation, it was envisaged to reduce the capacity of the storage system to 2 equivalent hours, which would reduce the investment cost very significantly.

Scenario 3 encompasses two different stages:

- Scenario 3(a): the use of GenSets allows an increase in the yearly payment for capacity (from $30 \mathrm{k} €$ to 60 $\mathrm{k} €)$, while the ESS is not modified;

- Scenario 3(b): the size of the ESS is changed to $2 \mathrm{~h}_{\mathrm{ec}}$ (instead of the previous $3 \mathrm{~h}_{\mathrm{eq}}$ ), reducing investment costs and changing the ESS activities and KPIs.

\section{Scenario 3(a)}

In Scenario 3(a), it should be noted that the operations of the ESS do not undergo any variation, since its characteristics do not vary. On the other hand, the possibility to operate through the GenSets, and to increase the payment received for the capacity made available in the mandatory period, allows to obtain a higher operating profit, decreasing the PBP and increasing the NPV. TABLE VI.3 presents the results obtained for Scenario 3(a).

TABLE VI.3 - RESULTS OF SIMULATIONS FOR SCENARIO 3(a).

\begin{tabular}{|c|c|c|c|c|c|}
\hline $\begin{array}{c}\text { Offer } \\
{[\boldsymbol{\epsilon} / \mathbf{M W h}]}\end{array}$ & $\begin{array}{c}\text { PBP } \\
{[\text { years] }]}\end{array}$ & $\begin{array}{c}\text { ESS Life } \\
{[\text { years] }}\end{array}$ & $\begin{array}{c}\text { NPV_10y } \\
{[\boldsymbol{\epsilon}]}\end{array}$ & $\begin{array}{c}\text { Profit } \\
{[€ / \text { year] }}\end{array}$ & $\begin{array}{c}\text { MWh } \\
\text { on ASM }\end{array}$ \\
\hline 150 & 8.91 & 4.90 & - & 188,110 & 1,737 \\
\hline 200 & 8.57 & 7.63 & - & 195,710 & 1,075 \\
\hline 250 & 9.20 & 11.63 & 49,428 & 182,245 & 681 \\
\hline 300 & 8.82 & 14.04 & 122,956 & 190,008 & 565 \\
\hline 350 & 8.91 & 17.36 & 105,650 & 188,181 & 458 \\
\hline 400 & 16.41 & 59.06 & 709,032 & 102,165 & 128 \\
\hline
\end{tabular}

$\underline{\text { Scenario 3(b) }}$

TABLE VI.4 shows results obtained for Scenario 3(b). In this case, GenSets are used to extend the range of the service.

TABLE VI.4 - RESULTS OF SIMULATIONS FOR SCENARIO 3(b).

\begin{tabular}{|c|c|c|c|c|c|}
\hline $\begin{array}{c}\text { Offer } \\
{[\boldsymbol{\epsilon} / \mathbf{M W h}]}\end{array}$ & $\begin{array}{c}\text { PBP } \\
{[\text { years] }}\end{array}$ & $\begin{array}{c}\text { ESS Life } \\
{[\text { years] }}\end{array}$ & $\left.\begin{array}{c}\mathbf{N P V} \\
{[\boldsymbol{[}]}\end{array}\right]$ & $\begin{array}{c}\text { Profit } \\
{[\boldsymbol{\epsilon} / \text { year] }}\end{array}$ & $\begin{array}{c}\text { MWh } \\
\text { on ASM }\end{array}$ \\
\hline 150 & 7.36 & 4.38 & - & 152,223 & 1,452 \\
\hline 200 & 6.88 & 6.85 & - & 162,986 & 884 \\
\hline 250 & 7.26 & 10.38 & 341,246 & 154,399 & 551 \\
\hline 300 & 7.01 & 12.72 & 394,450 & 160,016 & 451 \\
\hline 350 & 7.01 & 15.61 & 393,124 & 159,876 & 367 \\
\hline 400 & 11.97 & 49.50 & 234,234 & 93,638 & 103 \\
\hline
\end{tabular}

In front of a reduction of the capacity of the ESS from 3 to 2 equivalent hours, it is possible to observe that:

- the operating profit decreases, as the profit from the activities of the ESS is reduced by the amount corresponding to the reduction in capacity applied;

- the useful life of the ESS slightly decreases, which indicates a more intensive use of the ESS's capacity;

- the PBP decreases sharply, thanks to a significant reduction in the investment cost for the ESS, which however did not induce a significant decrease in terms of operating income (this is because the operating income is sustained by the payment in capacity which remains constant and guaranteed).

As a result of the above considerations, it is obtained that the NPV calculated over 10 years increases even if the annual profit decreases, which makes the investment profitable, especially if it is considered that for the offers of greater interest $(300-350 € / \mathrm{MWh})$ at the end of 10 years there is still a long period of useful life in which it is possible to continue to take advantage of the ESS. 


\section{CONCLUSIONS}

Evaluation and research activities, especially when it comes to the Italian case, are still needed to understand the major sectors for which Demand Response can be an effective economic opportunity. This work considers Data Centers as they are characterised by an intense and constant electric load; in addition, they are placed in consumption sites where UPS emergency generation units are typically present. Finally, it has to be considered that the importance of DC (and their unitary demand value) is expected to increase in the next future.

The simulations performed for the different scenarios underlined that a capacity remuneration is currently needed if Data Centers are required to adapt their energy infrastructures to provide ancillary services useful to the electricity network. Moreover, it has been highlighted how storage and generation units can be exploited locally, at the consumption site level, to couple local tasks they are currently called to perform, with system tasks they will be asked to cover in the next future.

In particular, considering a favourable regulatory framework (coherent with the ongoing pilot projects issued by TERNA in Italy) and an optimized sizing and management criterion for storage and generation units, the opening of the ASM to demand constitutes for Data Centers a good economic opportunity; also thanks to their great electricity needs, Data Centers can obtain an appreciable actualized profit by investing in the direction of ancillary services provision.

The profit calculated according to current ASM rules (energy only market) is not enough to justify investment costs required for the participation to the ASM (fixed costs). In this case, the economic opportunities are indeed very modest, and often come with high uncertainties, related to uneven market trends.

The calculations reported, based on real ASM market trend, lead to the conclusion that a capacity payment is needed, as it has been provided in the context of UVAC Italian pilot project: a fixed income could secure investment costs needed for allowing market participation (fixed costs), while the energy remuneration could lead to a supplementary profit (once variable costs, related to the operation of both UPS and GenSets, have been covered).

Further improvements of the present work should be focused on the possibility to consider different dispatching resources to be provided by Data Centers, in order to understand how customized services and remuneration mechanisms can constitute an advantage for both the electric system and the consumption units.

\section{ACKNOWLEDGMENT}

Authors thank the association Energy@home, that included the study presented here in a public report about the perspectives of Demand Response in Italy [19]. Authors also thank RSE [20] for the valuable discussions about the mathematical model on which the paper is based.

\section{REFERENCES}

[1] European Parliament, "Roadmap for moving to a competitive low carbon economy in 2050", $\operatorname{COM}(2011) 112,2011$, available at: eurlex.europa.eu

[2] Autorità di Regolazione per Energia Reti e Ambiente (ARERA), "Pubblico dibattito per la riforma delle modalità di approvvigionamento delle risorse per il servizio di dispacciamento, con particolare riferimento agli impianti di generazione distribuita e agli impianti alimentati dalle fonti rinnovabili non programmabili", Delibera 354/2013/R/EEL, available at: arera.it

[3] Autorità di Regolazione per Energia Reti e Ambiente (ARERA), "Prima fase della riforma del mercato per il servizio di dispacciamento: apertura alla domanda, alle fonti rinnovabili non programmabili e alla generazione distribuita", Documento Di Consultazione 298/2016/R/EEL, 9 June 2016, available at: arera.it

[4] Barbato, A., Capone, A., Carello, G., Delfanti, M., Falabretti, D., \& Merlo, M. (2014). A framework for home energy management and its experimental validation. Energy Efficiency, 7(6), 1013-1052.

[5] Barbato, A., Capone, A., Carello, G., Delfanti, M., Merlo, M., \& Zaminga, A. (2011, June). Cooperative and non-cooperative house energy optimization in a smart grid perspective. In World of Wireless, Mobile and Multimedia Networks (WoWMoM), 2011 IEEE International Symposium on a (pp. 1-6). IEEE.

[6] Directive 2009/72/CE of the European Parliament and Council, 13 July 2009, concerning common rules for the internal energy market and repealing Directive 2003/54/CE, available at: eur-lex.europa.eu

[7] European Commission (EC), Commission Regulation (EU) $2017 / 2195$ of 23 November 2017 establishing a guideline on electricity balancing (Text with EEA relevance), available at: eurlex.europa.eu

[8] Ministero dello Sviluppo Economico, "Strategia Energetica Nazionale 2017", available at: sviluppoeconomico.gov.it

[9] Autorità di Regolazione per Energia Reti e Ambiente (ARERA), "Monitoraggio dello sviluppo degli impianti di generazione distribuita per l'anno 2015", Allegato alla Delibera 278/2017/I/EEL, 20 April 2017, available at: arera.it

[10] European Commission (EC), "Rules of the European Parliament and of the Council on the internal market of electricity", $\operatorname{COM}(2016) 861$ final, 23 February 2017, available at: eur-lex.europa.eu

[11] Autorità di Regolazione per Energia Reti e Ambiente (ARERA), "Riforma organica della regolazione del servizio di dispacciamento dell'energia elettrica e conseguente attivazione del progetto interdirezionale rde (riforma del dispacciamento elettrico)", Delibera 393/2015/R/EEL, available at: arera.it

[12] Autorità di Regolazione per Energia Reti e Ambiente (ARERA), "Prima apertura del mercato per il servizio di dispacciamento (MSD) alla domanda elettrica e alle unità di produzione anche da fonti rinnovabili non già abilitate nonché ai sistemi di accumulo. Istituzione di progetti pilota in vista della costituzione del testo integrato dispacciamento elettrico (TIDE) coerente con il balancing code europeo", Delibera 300/2017/R/EEL, available at: arera.it

[13] TERNA, "Procedura approvvigionamento a termine risorse di dispacciamento per UVAC per il periodo 26 Giugno 2017 - 30 Settembre 2017 - capacità disponibile", terna.it

[14] Council of European Regulators (CEER), "Guidelines of good practice for flexibility use at distribution level”, Ref: C16-DS-29-03, Final Version, 14 March 2017, available at: smarnet-project.eu

[15] Avgerinou, Maria, Paolo Bertoldi, and Luca Castellazzi. Trends in data center energy consumption under the European code of conduct for data center energy efficiency. Energies 10.10 (2017): 1470

[16] Data Center classification available at: tia-942.org

[17] IRENA (2017), Electricity Storage and Renewables: Costs and Markets to 2030, International Renewable Energy Agency, Abu Dhabi, available at: irena.org

[18] Market public data related to Italian Power EXchange available at: mercatoelettrico.org

[19] Energy@home Association, “Partecipazione della Domanda Flessibile al Mercato del Servizio di Diaspacciamento, in Italian, February 2018, available at: energy-home.it

[20] Ricerca sul Sistema Energetico, rse-web.it 